\title{
Parasitological Day 2013: Parasites and other infectious agents of veterinary and human importance in the Alpe Adria region
}

\author{
Christoph Hörweg
}

Received: 16 September 2013 / Accepted: 12 January 2014 / Published online: 22 February 2014

(C) Springer-Verlag Wien 2014

The Austrian Society of Tropical Medicine, Parasitology and Migration Medicine (ASTPM, in German: ÖGTPM) holds every year the so called Parasitological Day (Parasitologische Fachgespräche). This year, the Parasitological Day took place in Carinthia, at the Carinthian Institute for Veterinary Disease Control in Klagenfurt, on 7 June, 2013. As the title suggests there was a focus on important parasites and infectious agents of this particular region. Another aim was to present the main working field of the inviting institute and to bring people together working in the same field, also and especially from neighboring countries. Thus, we were very happy to win colleagues not only from Austria, but also from Italy and Slovenia, and even Kenya, as speakers and participants.

The morning was filled with presentations, the first part dedicated to bacteria and viruses, mainly those important for life stock, and the second part dedicated to helminths (particularly those important for wild boar and fishes). The afternoon session of the Parasitological Day included an update on new diagnostic methods on one hand and case reports and demonstrations on the other hand. The day ended with a guided tour through the working facilities of the institute.

Hereby, we, the ÖGTPM, wish to thank the local organizers for their great hospitality (especially the head of the institute, Dr. Kurt Sick); we are already looking forward to come back to Carinthia again! We also wish to thank the sponsoring companies Biomedica and InVitro Labor.

The following abstracts (as compiled for the proceedings which have been handed out directly at the symposium) summarize the program of the Parasitological Day 2013.

Mag. C. Hörweg $(\varangle)$

Natural History Museum Vienna, 3. Zoology,

Burgring 7, 1010 Vienna, Austria

e-mail: christoph.hoerweg@nhm-wien.ac.at
Does parasite infestation in wild game influence paratuberculosis prevalence?

\section{Gunther Vogl', Heinrich Prosl ${ }^{2}$, Miroslav Vodnansky $y^{3,4}$}

${ }^{1}$ Carinthian Institute for Food Safety and Veterinary Disease Control, Klagenfurt, Austria

${ }^{2}$ Institute of Parasitology, Department for Pathobiology, University of Veterinary Medicine Vienna, Vienna, Austria ${ }^{3}$ Institute of Wildlife Ecology, University of Veterinary and Pharmaceutical Sciences, Brno, Czech Republic ${ }^{4}$ Central European Institute of Wildlife Ecology, Vienna-Brno-Nitra, Vienna, Austria

The working hypothesis of this ongoing long-term project is that the damage of the intestinal mucosa caused by parasites potentiates Mycobacterium avium subsp. paratuberculosis (MAP) infectiousness, and leads to accelerated infections and higher amounts of bacteria in the mucosa. Secondly, contaminated larvae of parasites, which migrate from the feces to the environment, might additionally spread the bacteria.

Consequently, treatment of game against intestinal parasites should decrease prevalence of Mycobacterium avium subspecies paratuberculosis (MAP) infections due to three reasons: (i) reduced damage of the mucosa, which poses a physical barrier for bacteria when being intact, (ii) higher resistance of individuals to infections due to better body condition, and (iii) less environmental contamination with MAP.

The study was started in 2011 and was conducted in three areas (designated A, B and C) harboring, among other wild game species, roe deer, red deer and moufflon, all of which samples were analyzed during the study. Fecal samples were collected in all areas and parasite infestation was examined with quantitative parasitological diagnostic methods. Additionally, nested polymerase chain reaction (nested PCR) was conducted for detection of MAP. The PCR assay included an inhibition control for highly reliable results. The assay was also applied on samples derived from hunted down animals. These samples included intestinal lymph nodes, colon mucosa, and rectal feces as sample material. The rectal feces were additionally examined with parasitological diagnostic methods.

To test the influence of deworming on the MAP prevalence, in two areas (A and B), the game was dewormed. Game in the third area (C) poses as untreated control group. Results of the first 2 years 
of investigations are rather preliminary. The overall parasite infestation was high, as expected, with Ostertagia spp. being the predominant nematodes in the digestive tract. The deworming process was conducted in late winter with two consecutive treatments with Fendbendazol at intervals of 4 weeks. Investigation of fecal samples a few weeks after treatment showed, that the deworming process was highly effective. Several Nematode species were not detected in samples after treatment. The prevalence of MAP in game, however, was not reduced after treatment, and is currently dramatically high with $100 \%$ of red deer tested positive in 2012 using a highly sensitive nested PCR method.

The project is going on for another 5 years. PCR analysis will be conducted again in the last 2 years of the study. In the meantime the sustainability of deworming will be controlled annually, based on data from hunted down animals.

\section{Prevalence of Mycobacterium avium subsp. paratuberculosis in dairy herds with paratuberculosis}

Mateja Pate, Katarina Logar, Jože Starič, Urška Zajc, Petra Bandelj, Brane Krt, Matjaž Ocepek

\section{University of Ljubljana, Veterinary Faculty, Ljubljana, Slovenia}

Paratuberculosis, a chronic infectious disease caused by $\mathrm{Myco-}$ bacterium avium subspecies paratuberculosis (MAP), which affects many animal species, is a common disease of ruminants in Slovenia. The first case was detected in 1961 in imported Jersey cows. No other cases were reported until 1993, when paratuberculosis was found in a sheep flock; since then, several outbreaks of the disease in cattle, goats, and sheep have been documented. Systematic screening of paratuberculosis was going on between 1995 and 2001, using various serological tests and including different categories and numbers of cattle. Between 2002 and 2007, no data on paratuberculosis prevalence have been available. In 2008, a seroprevalence study was conducted in which animals older than 2 years were screened for MAP in randomly selected cattle herds. The study showed that the true prevalence at the herd level was almost the same as in 1999 and that it was fairly low (18.49\%) compared with many European countries.

The results from our previous studies, concerning the comparisons of different diagnostic tests for paratuberculosis, suggested two main conclusions: (a) the specificity of the ELISA kits used is questionable, as in the majority of cattle herds with no evident clinical signs of infection and with no history or epidemiological link with paratuberculosis, there were no culture or polymerase chain reaction (PCR) positive animals despite about one tenth of seropositive animals; (b) there is a need for a highly sensitive and specific method to detect subclinically infected animals which are the main cause of maintained infection of a herd and of spread of infections between herds and premises. Lack of sufficiently sensitive, specific, reliable, and fast laboratory tests can lead to underestimation of the proportions of MAP shedders in herds.

Therefore, we recently introduced a high-yield DNA extraction method coupled with quantitative real-time PCR to detect MAP in cattle feces. The study, which included fecal culture, milk ELISA, milk qPCR, and fecal qPCR, was performed on the samples of 141 subclinically infected dairy cattle of all age categories from a farm with a history of paratuberculosis. The results suggested that the proportion of low-level MAP shedders in cattle populations tested in the past was most likely underestimated. In addition to detecting a surprisingly high proportion of MAP shedders within a herd (89\%), we demonstrated a negative influence of MAP infection to milk production already in the first lactation heifers. Due to its relatively high sensitivity and specificity, the developed qPCR can be applied to test for MAP at the herd or individual level, regardless of animal age or production stage. This was the first study on the importance of subclinical infections in dairy cattle in Slovenia, which will hopefully contribute to the improvement of the measures necessary to control the disease.

\section{Pathogenic agents causing abortion from a zoonotic and local point of view}

\section{Michael Dieter Mansfeld}

Carinthian Institute for Veterinary Disease Control, Klagenfurt, Austria

According to the title, the presentation is limited to abortion in ruminants, as some of the abortion agents of cattle, sheep, and goat have either a zoonotic potential or are transmitted via living vectors. The former poses a danger especially for farmers, veterinarians, and lab stuff, while the latter is difficult to eradicate from the population. As there are no vaccines available, vector borne abortion can only be handled by accompanying measures and gradually developing a certain immunity in the population against the pathogen.

In Carinthia the most important abort agents transmitted by vectors are Coxiella burnetii (different ticks, esp. Dermacentor marginatus), the Schmallenbergvirus (Culicoides spp.) and the blue tongue virus (Culicoides spp.). Abortion causing pathogens with zoonotic potential are primarily Brucella spp. (melitensis), Campylobacter spp. (fetus subsp. fetus, fetus subsp. venerealis, thermotolerant Campylobacter), Coxiella burnetii, Salmonella spp., Leptospira spp. and other bacteria with weak zoonotic potential (e.g., Chlamydia spp.).

Hence, veterinary surveillance is of prime importance. In Austria, different laws and orders concern abortion in cattle, amongst others the Morbus Bang law, the IBR/IPV law, and the BVD order is also included. According to these regulations, each abortion in cattle, with more than two cycles with insemination without pregnancy and suspicious symptoms, must be notified. Each person, who is able to recognize the disease, is obliged to report the officials as soon as possible. The lab analysis for Brucellosis, Trichomoniasis, IBR/IPV, BVD, and Mycoplasma are free of costs according to the legal situation.

As Austria is free from the mentioned plaques, normally an etiological finding cannot be obtained using only the officially paid analysis. So the motivation for the report of abortion in ruminants is rather less and only a small part of aborted fetus is reported.

Due to this, in Carinthia, the costs for necropsy of bovine fetus and placenta, pathohistology, overarching bacteriology, serology (IBR/IPV, Bang, BVD, Neosporosis), parasitology (Tritrichomonas fetus), and PCR (Schmallenbergvirus, Mycoplasma spp., Coxiella burnetii) are free (paid either by the local veterinary authority or the Carinthian Animal Health Association).

The local authorities take over the costs for certain investigations in sheep and goat (PCR: Schmallenbergvirus and Coxiella burnetii) as well. Therefore, from January 2012 to the end of April 2013 the Carinthian Institute for Veterinary Disease Control got 50 bovine fetus (with or without placental material), 14 caprine, and 23 sheep fetus for necropsy and further analysis. In literature you can read, especially in single abortion, that there is only a little detection rate of etiological relevant agents $(<40 \%)$. If the situation becomes more epidemic, the detection rate rises. The reasons may be amongst others an insufficient sample collection by the veterinarian, and, according to the costs, a deficiency of analysis or also insufficient techniques in the lab.

Sometimes it's difficult to estimate whether a detected agent is actually responsible for the present abortion. So how can we come to an etiological diagnosis? In the case of obligatory abort-causing pathogens the isolation or detection of the agents in the fetal organs and/or in the placenta by bacterial culture, PCR or pathohistology should be sufficient. Also, a significant increase of the antibody titer 
of the mother or the detection of specific antibodies in the immunecompetent fetus (blood, liquid of anterior eye chamber) can lead to an etiological diagnosis.

Much more delicate is the interpretation of the detection of facultative abortion, causing infectious agents (mainly bacteria). There should be a (almost) pure culture in fetal organs/placenta and fitting pathological and pathohistological lesions.

If there is a positive serology without increase of titer, this could nevertheless be an indication of the responsible agents:

- very high titers could be an evidence for an acute infection

- the infection could have taken place a time before

- the infection could also have been a latent infection

Important for the interpretation of the lab findings and also for the selection of the methods of analysis in use is the anamnesis. The following Figs. (1, 2, 3, and 4; compiled in spring 2011) give a short

\begin{tabular}{|c|c|c|c|c|c|c|}
\hline Aypes & Whenaty & Erovenume & Exth & 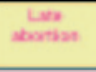 & 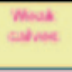 & 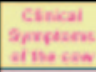 \\
\hline 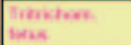 & + & + & + & - & - & + \\
\hline 7cos. yend & $?$ & $?$ & $?$ & $?$ & $?$ & (*) \\
\hline 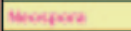 & . & (*) & + & + & + & $\cdot$ \\
\hline 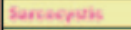 & - & $\cdot$ & (*) & (*) & - & (+) \\
\hline Burats & + & - & - & + & - & + \\
\hline Complusers. & . & + & (*) & - & - & - \\
\hline Gasents & . & $\cdot$ & . & + & + & (*) \\
\hline Onomoden & . & . & . & + & + & - \\
\hline Vposisuren & + & . & $(+)$ & + & . & + \\
\hline Answertasen & + & $\cdot$ & (*) & + & $\cdot$ & (+) \\
\hline 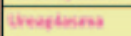 & (+) & - & $\cdot$ & . & $\cdot$ & (4) \\
\hline
\end{tabular}

Fig. 1 Infectious agents of abortion in cattle - part 1

\begin{tabular}{|l|c|c|c|c|c|c|}
\hline \multicolumn{1}{|c|}{ Agens } & Infertility & $\begin{array}{c}\text { Embryonatic } \\
\text { death }\end{array}$ & $\begin{array}{c}\text { Early } \\
\text { abortion }\end{array}$ & $\begin{array}{c}\text { Late } \\
\text { abortion }\end{array}$ & $\begin{array}{c}\text { Waak } \\
\text { calves }\end{array}$ & $\begin{array}{c}\text { Clinical } \\
\text { symptoms } \\
\text { of the cow }\end{array}$ \\
\hline Listeria mono. & - & - & - & + & $(+)$ & $(+)$ \\
\hline Loptospiren & - & - & - & + & + & $(+)$ \\
\hline Arcanob. pyog. & + & - & - & + & - & $(+)$ \\
\hline Salmonella & - & - & - & + & + & + \\
\hline Histophilus & - & - & - & + & + & $(+)$ \\
\hline Moulds & - & - & $(+)$ & + & - & - \\
\hline IBR/(IPV) & - & - & - & + & - & + \\
\hline BVD & - & + & + & + & + & $(+)$ \\
\hline Border disoase & - & - & - & - & - & - \\
\hline Blue tongue & - & - & $(+)$ & + & + & + \\
\hline Akabanevirus & - & - & - & - & + & - \\
\hline $\begin{array}{l}\text { Rift Valley } \\
\text { Fever }\end{array}$ & - & - & + & + & - & + \\
\hline
\end{tabular}

Fig. 2 Infectious agents of abortion in cattle - part 2

\begin{tabular}{|c|c|c|c|c|c|c|}
\hline \multirow[b]{2}{*}{ Erreger } & \multicolumn{6}{|c|}{ Abortuserreger beim kl. Wdk- kurze Übersicht } \\
\hline & $\begin{array}{l}\text { Unfucht } \\
\text { barkeit }\end{array}$ & $\begin{array}{c}\text { Embryonaler } \\
\text { Tod }\end{array}$ & Frühabort & Spätabort & $\begin{array}{l}\text { Lebens } \\
\text { schwache } \\
\text { Lammer }\end{array}$ & $\begin{array}{c}\text { Symptome } \\
\text { bei den } \\
\text { Muttertieren }\end{array}$ \\
\hline \begin{tabular}{|l}
$\begin{array}{l}\text { Tritrichom. } \\
\text { fetus }\end{array}$ \\
\end{tabular} & - & - & - & - & - & - \\
\hline Toxo. gondii & - & + & + & + & + & $(+)$ \\
\hline Neospora & $\cdot$ & - & $\cdot$ & $\cdot$ & . & - \\
\hline Sarcocystis & $\cdot$ & $\cdot$ & $(+)$ & $(+)$ & - & $(+)$ \\
\hline Brucella & + & $\cdot$ & . & + & + & + \\
\hline Camp. fetus & $\cdot$ & - & - & + & + & . \\
\hline Camp. jejuni & $\cdot$ & $\cdot$ & $(+)$ & + & . & $(+)$ \\
\hline Coxiella & - & $\cdot$ & $\cdot$ & + & + & $(+)$ \\
\hline Chlamydion & - & - & $\cdot$ & + & + & $\cdot$ \\
\hline Mykoplasmen & $\cdot$ & $\cdot$ & $\cdot$ & - & $\cdot$ & + \\
\hline Ureaplasma & + &. & - & - & - & $(+)$ \\
\hline
\end{tabular}

Fig. 3 Infectious agents of abortion in small ruminants - part 1 overview of the most important symptoms in abortion of ruminants either for method selection or for the interpretation of the findings.

In November 2011, the Friedrich Löffler Institute in Germany detected an Orthobunyavirus as source of abortion in cattle in Germany, which they then named "Schmallenbergvirus" according to the place of its first appearance. In September 2012, a countrywide serological testing brought out an almost nationwide high prevalence (serology) in cattle and small ruminants in Austria. Since autumn 2012, the Austrian government took over the costs for the analysis of Schmallenbergvirus via serology and PCR, as performed by the AGES. Since January 2013, the Carinthian Institute for Veterinary Disease Control does the Schmallenbergvirus-PCR by itself. The results of our analysis are shown in Figs. 5, 6, and 7.

In contrast with the rate mentioned in literature, the detection rate of relevant abortion causing pathogens was much higher. The etiological relevance of Aerococcus urinae in cattle abortion has

\begin{tabular}{|c|c|c|c|c|c|c|}
\hline Erreger & $\begin{array}{l}\text { Unfucht } \\
\text { barkeit }\end{array}$ & \begin{tabular}{|c|} 
Embryonaler \\
Tod
\end{tabular} & Frühabort & Spătabort & \begin{tabular}{|l} 
Lebens \\
schwache \\
Lämmer
\end{tabular} & $\begin{array}{c}\text { Symptome } \\
\text { bel den } \\
\text { Muttertieren }\end{array}$ \\
\hline Listeria mon/iv & $\cdot$ & - & - & + & $(+)$ & $(+)$ \\
\hline Leptospiren & - & - & - & + & + & $(+)$ \\
\hline Arcanob. pyog. & + & - & - & + & - & $(+)$ \\
\hline Salmonella & $\cdot$ & - & - & + & + & + \\
\hline Histophilus & $\cdot$ & - & - & + & + & $(+)$ \\
\hline Pilze & $\cdot$ & - & $(+)$ & + & - & - \\
\hline BER / (IPV) & - & . & . & - & - & . \\
\hline BVD & - & - & - & . & - & - \\
\hline Border disease & $\cdot$ & + & + & + & + & - \\
\hline Blue tongue & $\cdot$ & - & $(+)$ & + & + & + \\
\hline \begin{tabular}{|l|} 
Akabanevirus \\
\end{tabular} & $\cdot$ & . & - & $\cdot$ & . & . \\
\hline Naliobl sheep d. & $\cdot$ & . & + & $\cdot$ & $\cdot$ & + \\
\hline Riltalfilober & . & . & + & + & . & + \\
\hline
\end{tabular}

Fig. 4 Infectious agents of abortion in small ruminants - part 2

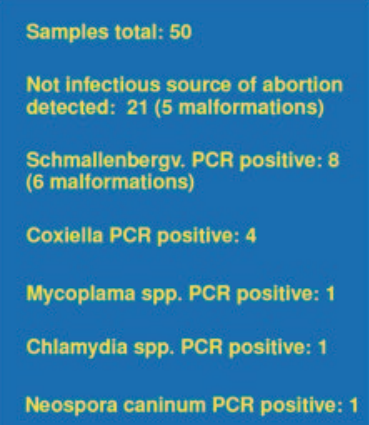

List. monozytog. culture positive: 2 Strept. spp. culture positive: 4 (1x Strept. equi subsp. zooepid.) Arcanobacterium pyogenes culture positive: 2

Aerococcus urinae culture positive: 4 (relevance?) Campylobacter jejuni subsp. jejuni culture positive: 1

Fig. 5 Abortion in cattle

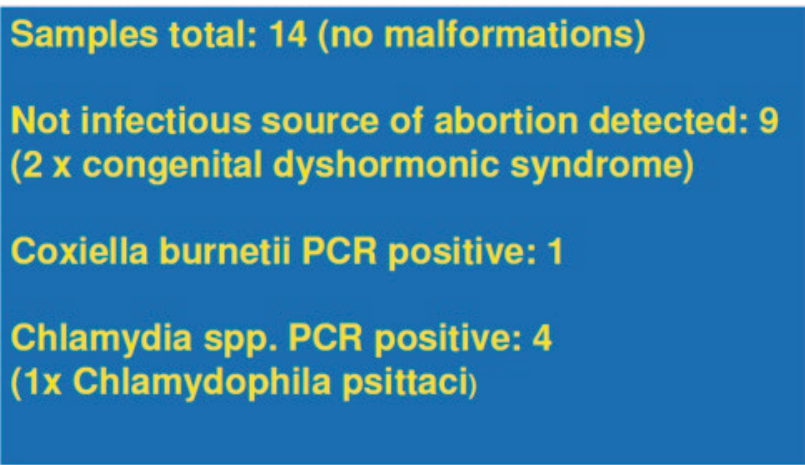

Fig. 6 Abortion in goat 


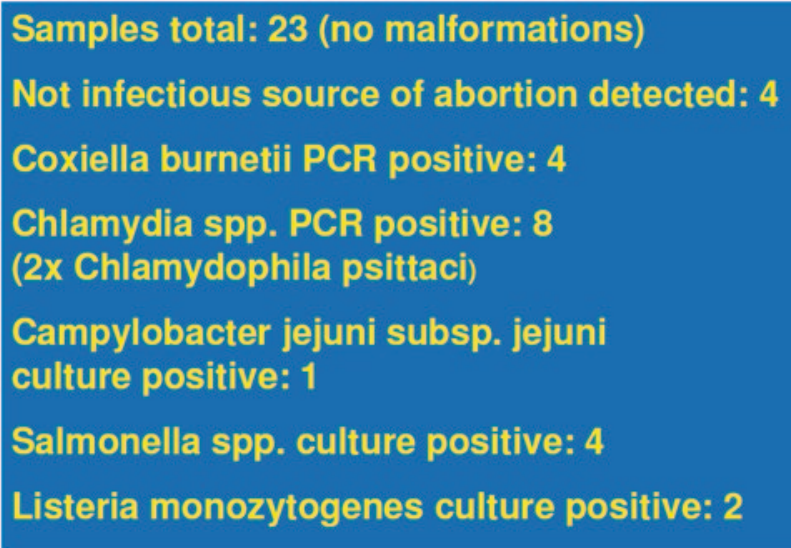

Fig. 7 Abortion in sheep

to be discussed, although there are some reports concerning their importance relating to infertility and abortion in herds namely in Scotland. The zoonotic potential of Chlamydophila psittaci, isolated in fetus of small ruminants is little (personal information of the European reference laboratory for Chlamydiaceae: there is no case of transmission of Chlamydophila psittaci from ruminants to humans reported). Highest attention must be paid to the exposure to Coxiella burnetii. There are also cases of human abortion reported after being in contact with Campylobacter fetus spp. of ruminants.

\section{Puumala-virus: a humanpathogen hantavirus in southern Styria}

\section{Gerald Ruckenbauer}

Medizinische Universität Graz, Institut für Hygiene, Mikrobiologie und Umweltmedizin, Graz, Austria

Hantaviruses, of the family Bunyaviridae, have been known for about 60 years and are spread worldwide. Approximately 300,000 illnesses are recorded annually. The group of human pathogenic hantaviruses include, among others, the Puumala virus, the Dobrava- and the Saaremaa virus. This enveloped single-stranded (-) RNA viruses cause various diseases depending on the type of virus. These include severe lung disease (pneumonia), acute renal failure (nephrotic syndrome), or hemorrhagic fevers.

All three virus types mentioned above have already been detected in Austria in humans and mice. The Puumala virus and the Saaremaa virus 2012 in Edlitz (Burgenland) and the Dobrava virus 2013 in Jenig (Carinthia) [1-3]. Most of the documented hantavirus infections occurred in Styria, Carinthia (especially in the district of Wolfsberg), in southern Burgenland, and the district of Rohrbach in Upper Austria between 1993 and 2010.

Since autumn 2011 a significant increase in the disease could be observed in Austria by the Puumala virus. In total, 32 Puumala virus infections were registered in 2011. Most cases, namely 21, appeared in Styria. Styria, Carinthia, and the Burgenland account to the high-risk areas. In the previous year, due to the proliferation of bank voles, a record increase in hantavirus infections has been observed. In 2012264 infections were diagnosed in Austria. These were seven and a half times as many cases as in 2011. A total of $90 \%$ of the cases were recorded in Styria and the remaining $10 \%$ in Carinthia, Burgenland, and Upper Austria.

The transmission of hantaviruses to humans is through the feces of rodents. The rodents drop out the virus in the urine, saliva, and feces for months in large quantities. As the pathogen remains infectious for a long period of time, a person can be infected mainly by inhaling dust through the lungs. Referring to the host animals, we can say that each hantavirus has its "own rodent" as a reservoir. Thus, for the Puumala virus Myodes glareolus is the reservoir and for the Saaremaa virus Apodemus agrarius, which is native mainly in the south-eastern Styria (Raabtal). The Dobrava virus is transmitted by Apodemus flavicollis, which occurs principally in the Balkans. However, all these mice species are native in Austria. They primarily inhabit the forest and areas nearby and are also found in large parks.

For prevention of infection rodents can be controlled in the field of human settlements. When cleaning it is recommended to use a mask and disposable gloves, because the viruses are transmitted through airborne dust. Wetting of affected areas, such as in sheds or barns, reduces the dust cloud. Places where mice lived should be well-ventilated and cleaned.

\section{References}

1. Aberle S. Hantavirus Infektionen in Österreich. Vir Ep Inf. 2012;8:3-5.

2. Aberle S. Hantaviren: Situation in den USA und in Österreich. Vir Ep Inf. 2012;18:2-5.

3. Aberle S. Hantavirus-Infektionen in Österreich. Vir Ep Inf. 2013;6:3-6.

\section{Elimination of rabies in Slovenia}

\section{Peter Hostnik}

University of Ljubljana, Veterinary Faculty, Ljubljana, Slovenia

In Slovenia, wildlife-mediated rabies has been present since 1973. Wildlife-mediated rabies has been present since 1973, first in the north-western part of Slovenia. A second wave of sylvatic rabies reached Slovenia in 1979 from Austria. From there it has been spreading throughout the country and has persisted until the present. The first pilot oral vaccination (ORV) trial was initiated in 1988 in several infected areas. Since 1995, large-scale rabies eradication programmes have been carried out throughout Slovenia, covering an area of some $18,800 \mathrm{~km}^{2}$ excluding high mountainous areas and urban developments (the whole country covers $20,273 \mathrm{~km}^{2}$ ). Two vaccines were distributed in the field from 1998 to 2004, namely Lysvulpen $^{\circledast}$ and Fuchsoral ${ }^{\circledast}$. Since 2005 , only Fuchsoral ${ }^{\circledast}$ has been used. Baits were dropped by fixed-wing aircraft twice a year in spring (May-June) and autumn (September-October) using an average bait distribution density ranging from $22-28$ baits $/ \mathrm{km}^{2}$. From 2008 to 2012, more than 4 million baits were distributed throughout Slovenia. After each ORV campaign, results were monitored by collecting foxes in vaccinated areas to evaluate the efficacy of vaccination through rabies incidence, bait uptake (revealed through a tetracycline biomarker) and the rabies immunisation rate of fox populations. From 2008 to 2012, a total of 107 field samples found positive for rabies virus through a fluorescent antibody test were sequenced and retested with a panel of monoclonal antibodies that discriminate between the SAD B19 strain and a wild-type rabies virus circulating in Slovenia.

In the rabies surveillance program in 1995, 1,089 rabies-positive animals were detected in Slovenia, but in the period between 1998 and 2007, the number of positive samples decreased from 15 to 2 cases per year. The majority of rabies cases in the years 2008 ( 55 positive), 2009 (35 positive) and 2010 (17 positive) were detected along the border with Croatia, where vaccination was not performed in this period. In 2011, 2012 and 2013 only 0,3 and 1 respectively rabid animals were detected. 
The collected samples have been tested each year for the presence of rabies virus and selected samples have also been tested for bait up-take (biomarker) and rabies virus-specific antibodies. All rabies virus positive samples were typed as field or vaccine strain by indirect immunofluorescence test using monoclonal antibodies and also by partial sequencing of $\mathrm{N}$-gene of viral genome.

When analysing all positive samples by indirect FAT using panel of anti-nucleocapsid MAb's for field and vaccine rabies virus discrimination, only two samples were found to be vaccine related. A molecular epidemiology study performed on a collection of rabiespositive brain samples from 1994 to 2010 in Slovenia showed little genetic diversity in the circulating strains, which all belong to two groups of closely-related strains (Western (WE) and Eastern (EE) European groups). When comparing partial glycoprotein gene rabies positive samples from Slovenia showed the same topology comparing the results in N gene with 94.6-100\% nucleotide homology to each other and form two genetic groups. Comparing to other European isolates (strains 9202ALL from Germany, 9244FRA from France) our positive samples have $96.4-98.4 \%$ nucleotide homology.

During the period of 2007-2010 in total 4,683 jaw samples of red foxes were collected. On average $75.75 \%$ of tested foxes older than 6 months were positive for biomarker with values ranging from $70.15 \%$ in 2007 to up to $80.05 \%$ in 2010 . The percentage of bait uptake in foxes younger than 6 months in the same period was $28.35 \%$. During the same period, 1,241 thoracic liquid samples or blood of red foxes were analysed and $58.35 \%$ of those were positive to rabies antibodies.

According the results and anti-rabies activities in all neighbouring countries we can expect, that in Slovenia the rabies will be eradicated during few following years.

\section{West Nile virus in north eastern Italy}

Paolo Mulatti Fabrizio Montarsi, Lebana Bonfanti, Gioia Capelli, Stefano Marangon

Istituto Zooprofilattico Sperimentale delle Venezie, Legnaro (Padua), Italy

Since 2008, West Nile virus (WNV) has been spreading in several Italian regions and its yearly recurrence suggests the virus may have become endemic in north-eastern part of the country. In 2011 and 2012 a new surveillance plan based on the detection of IgM antibodies was implemented in the north-eastern Italian regions of Veneto and Friuli Venezia Giulia, aiming in the early detection of WNV infections in areas where the virus was already circulated during the previous summers, and in adjacent zones. The surveillance season lasted from July to November both in 2011 and 2012. A total of 521 and 848 equine premises were screened by a commercial IgM capture ELISA in 2011 and 2012, respectively. Entomological surveillance was carried out by capturing mosquitoes with CDC-CO traps. Collected mosquitoes were identified, pooled by species/date/location and examined by real-time polymerase chain reaction (RT-PCR) and sequencing. Sixty-one traps were located in the two regions in 2011 and activated biweekly from the first week of May to mid November for a single night. In 2012, the traps were reduced to 39 and located in the area considered at higher risk of WNV spread. In both years passive surveillance was carried out on clinically affected horses and non-migratory wild birds found dead. A total of 19 and 18 equine premises tested positive for IgM against WNV in 2011 and 2012, respectively. Entomological surveillance detected WNV in 5 pools out of a total of 2,732 tested pools in 2011 and in 13 out of 2,989 pools in 2012. Passive surveillance on nonmigratory wild birds allowed detection of the virus only in one found dead collared dove (Streptopelia decaocto) in 2011 and in a total of
13 birds in 2012 (9 magpies, Pica pica; 1 hooded crow, Corvus corone cornix; 2 Eurasian skylark, Alauda arvensis; and 1 red-breasted goose, Branta ruficollis). A lineage two WNV was identified in 2011 in two mosquito pools and in the positive collared dove; a lineage two WNV was also detected in one mosquito pool in 2012. Phylogenetic analyses showed that the 2012 lineage two WNV strain was divergent from the WNV lineage two strain detected in Italy in 2011 (strain Hungary/04), whereas it had a very high similarity with the viral strain circulating in Greece in 2012 (Nea Santa-Greece/2010). The identification of several different strains suggests that, beside the risk of endemisation, new introductions may occur cyclically. The evolution of the epidemiological situation in the last 2 years stresses the need for continuous and fine-tuned surveillance procedures. The implementation of a protocol combining IgM screening of horses with surveillance on mosquito vectors could prove valuable for early detecting WNV circulation or reactivation.

\section{Trichinella pseudospiralis in wildboars (Sus scrofa) of the Friuli Venezia Giulia region, Italy}

Gabriella Conedera1, Denis Vio', Martina Ustulin', M. Londero', Marco Bregoli', Gianni Perosa', Silvia Rigo', Giulia Simonato ${ }^{3}$, Stefano Marangon ${ }^{4}$, Maria Interisano ${ }^{5}$, Maria Angeles Gomez Morales ${ }^{5}$, Edoardo Pozio ${ }^{5}$, Gioia Capelli ${ }^{4}$

${ }^{1}$ Istituto Zooprofilattico Sperimentale delle Venezie, SCT4 Friuli VG, Italy

${ }^{2}$ Local Health Unit, Veterinary Service ASS 04 Medio Friuli, Udine, Italy

${ }^{3}$ Dipartimento di Medicina Animale, Produzioni e Salute (MAPS), University of Padua, Italy

${ }^{4}$ Istituto Zooprofilattico Sperimentale delle Venezie, SCS3

Legnaro (Padua), Italy

${ }^{5}$ European Union Reference Laboratory for Parasites, Istituto Superiore di Sanità, Rome, Italy

Four Trichinella species have been detected in Europe to dateT. spiralis, T. nativa, T. britovi and T. pseudospiralis-but only T. britovi is endemic in Italy, mainly confined to wildlife. T. pseudospiralis is a non-encapsulated species with cosmopolitan distribution, representing a potential threat for human health for its wide host range (mammals and birds) and pathogenicity.

In Italy, until 2010 T. pseudospiralis was reported only in two night-birds of prey in Central Italy [1]. This paper describes a $T$. pseudospiralis focus in wild boars, bred outdoors in a confined small area of the Udine province in the Friuli VG region. In January 2010, two out of three slaughtered wild boars $(70-80 \mathrm{~kg})$ tested positive for Trichinella sp. larvae under routine controls according to the Commission Regulation 2075/2005. The larval burden in the diaphragm pillars of two wild boars was 38 and 185/g, respectively. Trichinella sp. larvae were identified as T. pseudospiralis by a multiplex polymerase chain reaction (PCR) performed at the EURL for Parasites, Rome, Italy.

These two cases, along with another one detected in a hunted wild boar of the Emilia Romagna Region in January 2010 as well, represented the first report of T. pseudospiralis in mammals of Italy. The two T. pseudospiralis-positive wild boars were reared with other eight wild boars aged 1-14 years, in a small outdoor farm located at $200 \mathrm{~m}$. a.s.l.. They were kept in an uncovered fenced area with trees and a small pond, within a hilly territory characterized by a well-conserved wildlife population (red foxes, mustelids and many species of birds, including waterfowls). Nearby, there was a small trout farm owned by the same farmer. The farmed wild boars were fed with vegetables, maize, and occasionally some dead trouts; the use of kitchen waste was excluded. 


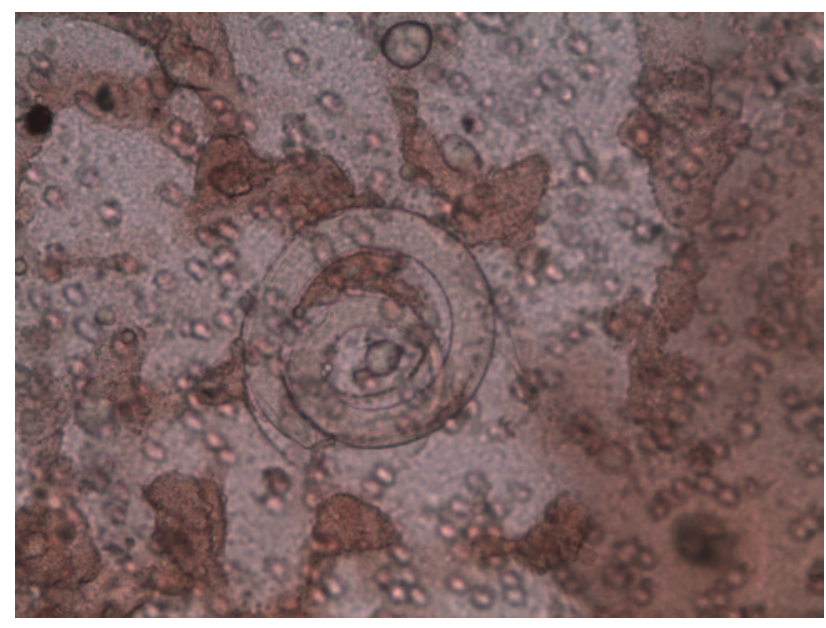

Fig. 1 Trichinella pseudospiralis larva after artificial digestion

The farmer usually slaughtered 2-3 wild boars per year and part of the meat was processed into salami for the family consumption. After the detection of T. pseudospiralis larvae, the batch of salami produced with the positive carcasses was immediately confiscated. For experimental purposes, two salamis tested after 35 days of seasoning were digested, and four nonmotile larvae/g were detected (see Fig. 1). Four laboratory mice were fed with $10 \mathrm{~g}$ of 35 -day cured salami for 3 consecutive days, sacrificed, and tested after 60 days. No larvae were detected, confirming the non-infectivity of the larvae.

In February 2012, a third T. pseudospiralis positive wild boar reared in the same farm was detected. It was a 2-year-old sow, born in March 2010, i.e., after the detection of the previous two cases, indicating a different exposure to the source of infection. The mean number of larvae per gram of muscle ranged from 0.22 to 1.8 , with the highest concentration in the diaphragm, followed by shoulder and neck muscles.

In January 2013, a fourth T. pseudospiralis positive wild boar reared in the same farm was detected after an episode of Salmonella choleraesuis. Out of 17 wild boars present at the farm, 4 had died for septicemia and 13 were slaughtered for the farm depopulation. The positive animal was a female of $76 \mathrm{~kg}$. The larval burden in the

Table 1 Wildlife monitoring in north eastern Italy (Veneto and Friuli VG regions, Trento and Bolzano provinces); in brackets data referred to the Friuli VG region alone

\begin{tabular}{|c|c|c|c|c|c|c|c|c|}
\hline \multirow[t]{2}{*}{ Species } & \multicolumn{2}{|l|}{2009} & \multicolumn{2}{|l|}{2010} & \multicolumn{2}{|l|}{2011} & \multicolumn{2}{|l|}{2012} \\
\hline & Tested & $\begin{array}{l}\text { Pos- } \\
\text { itive }\end{array}$ & Tested & $\begin{array}{l}\text { Posi- } \\
\text { tive }\end{array}$ & Tested & $\begin{array}{l}\text { Posi- } \\
\text { tive }\end{array}$ & Tested & $\begin{array}{l}\text { Posi- } \\
\text { tive }\end{array}$ \\
\hline \multirow{2}{*}{$\begin{array}{l}\text { Wild } \\
\text { boar } \\
\text { (hunted } \\
\text { and } \\
\text { farmed) }\end{array}$} & 2907 & 0 & 3912 & 2 & 3233 & 0 & 4950 & $1^{* \star}$ \\
\hline & (1613) & & (2158) & $(2)^{\star \star}$ & (1625) & & (2662) & $(1)^{\star *}$ \\
\hline \multirow[t]{2}{*}{ Fox } & 159 & $1^{*}$ & 971 & $2^{*}$ & 1069 & $2^{*}$ & 1809 & 3 \\
\hline & (24) & & (263) & $(1)^{*}$ & (283) & & (501) & $(1)^{\star}$ \\
\hline \multirow{2}{*}{$\begin{array}{l}\text { Muste- } \\
\text { lids }\end{array}$} & 54 & 1 & 264 & 0 & 551 & 0 & 527 & 0 \\
\hline & (2) & & (20) & & (40) & & (49) & \\
\hline Corvids & & & (389) & 0 & & & & \\
\hline
\end{tabular}

diaphragm pillars was $115 / \mathrm{g}$. Serum samples from the 17 wild boars were tested for Trichinella antibodies by both ELISA and WB at the EURLP. The serum samples from three wild boars were positive even if no Trichinella sp. larvae had been detected in two of them by digestion.

In all the four cases, the source of infection was unknown. We can argue that a carnivore mammal or bird had entered the fenced area or that unknown people have thrown T. pseudospiralis infected scarps or offal of hunted wild boars in the fenced area. Since 2006, when the artificial digestion method was routinely used, T. pseudospiralis had never been detected in wild or farmed animals of the Friuli VG region. Only $T$. britovi was occasionally detected in red foxes (Vulpes vulpes) of the Friuli VG region (Table 1).

This case report shows that T. pseudospiralis is circulating among wildlife in Northern Italy. It is difficult to know if it is an emerging species in Italy and in Europe or if it is just more prevalent than previously thought because of the improvement of the detection methods which switched from the trichinoscopy to digestion according to the Commission Regulation 2075/2005. Trichinella monitoring programs in wildlife reservoir species could further elucidate epidemiological aspects related to T. pseudospiralis.

\section{Reference}

1. Pozio E, Goffredo M, Fico R, La Rosa G. Trichinella pseudospiralis in sedentary night-birds of prey from Central Italy. J Parasitol. 1999;85:759-61.

\section{Parasitological investigations of brown trouts (Salmo trutta) in the Slovenian and Carinthian Karawanke}

\section{Robert Konecny', Margrit Jütte' ${ }^{2}$, Samo Podgornik³ Martin Konar ${ }^{4}$, Wolfgang Honsig-Erlenburg ${ }^{5}$}

'Department of Surface Waters, Environment Agency Austria, Vienna, Austria

2Department of Limnology, University of Vienna, Vienna, Austria ${ }^{3}$ Fisheries Research Institute of Slovenia, Ljubljana- Šmartno, Slovenia

${ }^{4}$ Kärntner Institut für Seenforschung, Naturwissenschaftliches Forschungszentrum, Kirchengasse, Klagenfurt, Austria

${ }^{5}$ Amt der Kärntner Landesregierung, Abt. 8-Umwelt, Wasser und Naturschutz; U.Abt. Ökologie \& Monitoring, Klagenfurt, Austria

Within the ETZ Project KARAFISH "Altitudinal distribution of brown trout and occurrence of bullhead in the Karawanke" a parasitologiocal survey of brown trouts was performed. From October 2011 to March 2013, fifteen specimens of brown trout from Slovenia and 28 brown trout from Caranthia were investigated for the presence of metazoan parasites. During this study, parasites of the groups Monogenea, Digenea, and Nematoda were found. For the most abundant parasite species prevalence, mean intensity and mean abundance was calculated. Fish from locations with altitudes higher than $800 \mathrm{~m}$ showed either a very low infection with nematodes or no parasites at all. Differences of the parasite communities of locations in Slovenia and Carinthia are discussed in the light of the complex life cycles of the parasites and differences of the fish populations. 


\section{Parasites of commercially important fish from Lake Naivasha, Rift Valley, Kenya}

\author{
Elick O. Otachi ${ }^{1,3}$, Adiel E. M. Magana ${ }^{2}$, Franz Jirsa ${ }^{4,5}$, \\ Christine Fellner-Frank
}

${ }^{1}$ University of Vienna, Department of Evolutionary Biology, Vienna, Austria

${ }^{2}$ Chuka University College, Faculty of Science, Chuka, Kenya ${ }^{3}$ Egerton University, Biological Sciences Department, Egerton, Kenya

${ }^{4}$ University of Vienna, Institute of Inorganic Chemistry, Vienna, Austria

${ }^{5}$ University of Johannesburg, Dept. of Zoology, South Africa

In Lake Naivasha the common carp Cyprinus carpio L. 1758, was accidentally introduced from fish farms adjacent to River Malewa in 1999 and now forms the bulk of the total fish caught. Since its introduction, there was neither any study on its parasitic community nor are there any reports on ectoparasites from other fish species in this lake to the best of our knowledge. Therefore, the aim of this study was to describe the parasitic community of C. carpio and two other commercially important fish species; Oreochromis leucostictus and Tilapia zillii. Additionally, the abundant Barbus paludinosus was included in the study. A total of 286 fish (145 C. carpio, 56 O. leucostictus, $18 \mathrm{~T}$. zillii and $67 \mathrm{~B}$. paludinosus) were collected during the year 2011 and examined. A total of 10 taxa of parasites were recovered from C. carpio dominated by the monogenean Dactylogyrus minutus, occurring with a prevalence (p) of $99.3 \%$. A total of 13 taxa of parasites were identified from $O$. leucostictus dominated by monogeneans Cichlidogyrus spp. $(\mathrm{p}=91.1 \%)$. T. zillii harbored 9 taxa of parasites with the digenean Tylodelphys $\mathrm{sp} .(\mathrm{p}=83.3 \%)$ being dominant and B. paludinosus harbored 11 taxa of parasites dominated by an unidentified monogenean of the genus Dactylogyrus $(\mathrm{p}=83.6 \%)$. C. carpio had the lowest helminth species diversity and richness while monogenetic trematodes which have never been reported from fish in Lake Naivasha were the most prevalent parasites recovered.

SVANOVIR: Fasciola hepatica antibody test: predicting the economic impact of Fasciola hepatica

\section{Monika Mellert}

Biomedica Medizinprodukte GmbH \& CoKG, Vienna, Austria

Anthelmintic resistance is a growing problem (FVE Board Meeting; March 2013).

Veterinarians and farmers need to work out strategic treatments based on context of animal health plans instead of mass treatments. Cattle takes up different loads of the parasite during grazing and within a herd individuals can be negative, have mild, moderate or severe infection.

Studies from the University in Ghent on dairy and beef cattle have shown that only moderate to high worm burden leads to production loss. Additionally the researcher found out that there is a positive correlation between worm burdens. Antibody levels in milk, serum and meat juice, giving us now the opportunity to determine an "economic threshold" [1,2].

Values above the economic threshold point (defined in the cutoff of the ELISA) at herds and individuals that are moderately to severely infected will most likely cause production loss in the future.
This ELISA Test gives the possibility to classify herds and individuals for predicting economic consequences of infection. The aim is the reduction of the infection to levels where there is no or minimal interference with the productivity of the cattle. It is a management tool for veterinarians and farmers in controlling fasciolosis with targeted and rational use of anthelmintic.

The indirect ELISA based on the excretory/secretory (E/S) antigen of F. hepatica parasite has been validated in bovine for milk (individual and bulk tank), serum and meat juice and thus giving the opportunity to monitor at different stages of the milk/beef production chain (farms, dairies and slaughterhouses).

\section{References}

1. Charlier J, Duchateau L, Claerebout E, Williams D, Vercruysse J. Associations between anti-Fasciola hepatica antibody levels in bulk-tank milk samples and production parameters in dairy herds. Prev Vet Med. 2007;78:57-66.

2. Charlier J, De Cat A, Forbes A, Vercruysse J. Measurement of antibodies to gastrointestinal nematodes and liver fluke in meat juice of beef cattle and associations with carcass parameters. Vet Parasitol. 2009;166:235-40.

The use of direct polymerase chain reaction for the molecular analysis of parasites and vectors

\section{Hans-Peter Fuehrer}

Institute of Parasitology, Department for Pathobiology, University of Veterinary Medicine Vienna, Austria

Over the past decades, the devastating effects caused by vector borne diseases (VBDs) on humans and animals as well as their impact on the economy has been felt globally. Mosquitoes are considered as the major actors in the transmission of VBDs. Invasive mosquito species are proven vectors of not only the newly introduced but also of autochthonous parasites and other VBDs. Their expansion to Central Europe is promoted primarily by factors like climate change and passive transport. For example, the European Centre for Disease Prevention and Control (ECDC) risk maps indicate the Asian tiger mosquito (Aedes albopictus) as one of the world's 100 most dangerous invasive species. Several mosquitoes common in Central Europe serve as carriers of VBDs such as invasive Dirofilaria nematodes. However, little is known about vectors and parasites, including their distribution patterns and molecular phylogeny.

For diagnosis and phylogenetic analysis, of both vectors and parasites, novel molecular techniques are needed. These should not only provide accurate results but also save time and samples (e.g., use of one mosquito leg only). In the past decades the improvement of molecular diagnostic tools (e.g., polymerase chain reaction (PCR), real-time PCR) has resulted in the availability of far more sensitive tools (e.g., Direct PCR). The use of Direct PCR allows for PCR amplifications without any prior DNA extraction and purification steps. The Phusion blood DNA polymerase used in the assay is reported to lead to a 25 -fold lower error rate in comparison with common Thermus aquaticus polymerase. The aim of this study is to adapt this novel technique for use in the rapid lab-based diagnosis of parasites and vectors and validate the sensitivity in comparison with conventional diagnostic techniques (e.g., standard PCR). 
Parasitological cases investigated at the Landesanstalt

\section{Michael Dieter Mansfeld}

Carinthian Institute for Veterinary Disease Control, Klagenfurt, Austria

In the last few years, we could see an increasing number of vector-borne diseases (VBD) that maybe or can be related to the climate change. We find an increasing number of blood parasites such as Leishmania, Dirofilaria, Babesia, and Anaplasma namely in pets, and diseases in farming animals such as the blue tongue disease in Central Europe. So, this presentation is addicted to the appearance of new parasitic agents in Carinthia, which can possibly be associated with the climate change.

In 2009, in Diex (Lavanttal), we saw suddenly emerging cases of skin hemorrhages in cattle with, at the beginning, unknown etiology. The cases then spread over the whole Lavanttal. In the following years also surroundings of St. Veit and Feldkirchen were affected.

At almost the same time (2009) there was a sudden emergence of skin bleeding in calves in Germany with also at first unknown etiology. After months of scientific perplexity the bovine virus diarrhea (BVD) vaccination with alive vaccine of the mother cows was suspected as the cause of the bleeding.

As the situation in Austria is different, the vaccination against BVD is prohibited; there is only stamping out of affected cattle, after exclusion of possible illegal vaccination or illegal import of vaccinated cattle, we could exclude the idea of BVD vaccination as source of the bleeding in Carinthian cattle. By means of cytology and pathohistology we detected Parafilaria bovicola as the etiological responsible pathogen.

Parafilaria bovicola is a filarial parasite of cattle and water buffalo, which is transmitted by flies of the genus Musca. The adult female worm is up to $65 \mathrm{~mm}$ long, and the male $35 \mathrm{~mm}$. The flies deposit their eggs on small bleeding lesions of the skin. The development from the egg to the adult worm takes around 10-12 days. The adult female worm produces a small nodule and perforates the skin of the cattle. The diagnosis can be made by the detection of the eggs or larvae in the blood of the skin lesion. We also find a seasonal appearance of the hemorrhage according to the development of the flies. In the past Parafilaria bovicola was endemic only in Asia, Africa, and some European countries such as Bulgaria, Romania, France, and Sweden.

In Carinthia at first all affected animals were imported Charolais from France or Sweden. Since the first appearance, the disease became endemic in some districts of Carinthia. In this case the transnational animal trade and not the climate change was responsible for the emerging of this new VBD.

\section{Brucella melitensis: a case report}

\section{Eva Ratschek}

Institut für Krankenhaushygiene und Mikrobiologie, Graz, Austria

Brucellosis is a rare disease in Austria. Most brucellosis infections are acquired abroad and brought back to Austria. With a case report of a recent Brucellosis the difficulty of the microscopical detection of the slow growing bacteria Brucella melitensis is discussed.

A 47-year-old man shows the following symptoms weeks after his return from Bosnia: recurrent fever, polyarthralgia, cephalea, and night sweats. During hospitalization the patient suffers from abdominal pains, testicle pains, and arthralgia in the right hip and foot. His fever keeps sustaining and on that account, blood cultures are done. At first the blood cultures remained negative but later on they became positive with very small gram-negative rods. The detection of brucellosis can be a challenge due to the rareness of the infection in Austria and the slow growth of the bacteria on culture media and the difficult microscopical detection.

The patient was diagnosed with Brucella melitensis and treated with rifampicin and doxycycline. The patient reentered the hospital again with recurrent fever, tiredness, and headache, 4 months later. Again, he was diagnosed with Brucella melitensis, which was determined by blood cultures. This time, the patient was treated again with rifampicin, doxycycline, and additionally with amikacin. The patient seems to be cured so far.

DNA-sequencing showed that the Brucella melitensis strains were the same. During the 4 months the man went back to Bosnia for holiday, so it is difficult to say if it was a reinfection with the same strain or an ongoing infection.

\section{Demonstration: watersnails, cercarial release experiments, cercariae}

\section{Christoph Hörweg, Helmut Sattmann}

Naturhistorisches Museum Wien, 3. Zoologische Abteilung, Vienna, Austria

To prove the diagnosis of cercarial dermatitis, cercarial release experiments, which means a direct evidence of cercariae which have been released from the intermediate host, the lymnaeid water snail, can be provided. First collect the freshwater snails from the relevant waterbodies (e.g., ponds, lakes, swimming ponds). Relevant species are for example the great pond snail Lymnaea stagnalis, the great ram's horn snail Planorbarius corneus or pond snails of the genus Radix.

For transportation use buckets with little water and keep them as cool as possible. In the lab put the snails individually in separate glasses and place them under artificial light or on the window for natural light for approximately $24 \mathrm{~h}$. Afterwards you'll find "white trembling dots" within the water (see Fig. 1). To observe/determine them you will need at least a stereomicroscope or the better a translucent microscope (for sufficient magnification). That's the direct proof of the medical agent $=$ cercariae. But be aware that only a few species are causing cercarial dermatitis, most are parasites of birds, amphibians, or fishes and do not affect humans.

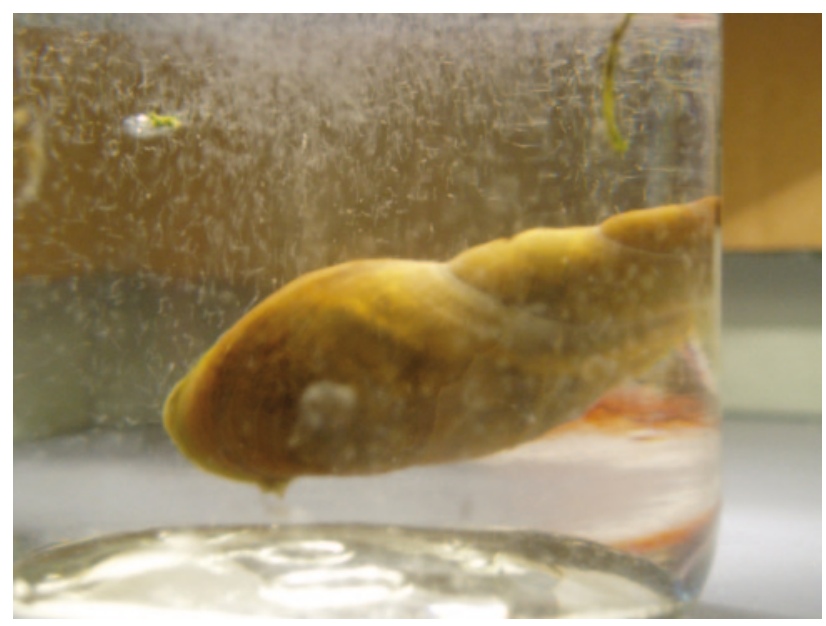

Fig. 1 Lymnaea stagnalis shedding hundreds of cercariae 


\section{Dirofilariae: Knott-test}

\section{Georg Duscher}

Institute of Parasitology, Department for Pathobiology, University of Veterinary Medicine Vienna, Austria

Procedure (modified after Genchi et al. [1]):

1. $1 \mathrm{ml}$ anticoagulated dog blood (EDTA or heparin) $+9 \mathrm{ml}$ forma$\operatorname{lin}(2 \%)$

2. Mix

3. Centrifuge for $5 \mathrm{~min}$ at $300 \mathrm{xg}$.

4. Remove $9 \mathrm{ml}$ of supernatant

5. Mix sediment with one drop methylene blue $(0.1 \%)$

6. Place liquid on a slide, cover with a coverslip

7. Examine under microscope

Interpretation: With this technique microfilariae can be found in the blood. Erythrocytes are destroyed by the formalin, thus facilitating screening for the larvae. Furthermore, the methylene staining increases the contrast, consequently increasing the visibility of the faint coloured larvae.

Do not use as stand-alone diagnostic test!

Positive test: Microfilariae could be the progeny of other nematodes (Table 1). They could also be transferred prenatally.

Negative test: Infections with only male or only female worms do not show microfilariae in the blood. Immature females start pro-
Table 1 Other nematodes relevant for differential diagnosis of Dirofilaria (after Genchi et al. [1])

\begin{tabular}{|l|l|l|}
\hline Species & Length $(\mu \mathrm{m})$ & Caudal end \\
\hline Dirofilaria immitis & $290-330$ & Straight, end point \\
\hline Dirofilaria repens & $300-360$ & "Umbrella handing" \\
\hline Acanthocheilonema reconditum & $260-283$ & Hooked and curved \\
\hline Acanthocheilonema dracunculoides & $190-247$ & Sharp and extended \\
\hline Cercopithifilaria grassii & 567 & Slightly curved \\
\hline
\end{tabular}

ducing microfilariae after $\sim 6$ months. In cats the shedding of the microfilariae is not reliable.

\section{Reference}

1. Genchi C, Venco L, Genchi M. Guideline for the laboratory diagnosis of canine and feline Dirofilaria infections. In Genchi C, Rinaldi L, Cringoli G, editors. Mappe Parassitologie 8-Dirofilaria immitis and Dirofilaria repens in dog and cat and human infection. Neapel: Rolando Editore; 2007. 137-44.

\section{Conflict of interest}

The authors declare that there are no actual or potential conflicts of interest in relation to this article. 